\title{
Effects of CNT diameter on mechanical properties of aligned CNT sheets and composites
}

\author{
Tran Huu Nam" ${ }^{\text {ab* }}$ Ken Goto ${ }^{a}$, Yudai Yamaguchic, E.V.A. Premalal ${ }^{c}$, Yoshinobu \\ Shimamura ${ }^{\mathrm{c}}$, Yoku Inoue $^{\mathrm{c}}$, Kimiyoshi Naito $^{\mathrm{d}}$, Shinji Ogihara ${ }^{\mathrm{e}}$ \\ ${ }^{a}$ Department of Space Flight Systems, Institute of Space and Astronautical Science, Japan Aerospace Exploration Agency, 3-1-1 \\ Yoshinodai, Chuo, Sagamihara, Kanagawa 252-5210, Japan \\ ${ }^{b}$ Faculty of Fundamental Sciences, PetroVietnam University, Long Toan, Ba Ria, Ba Ria - Vung Tau 790000, Viet Nam \\ ${ }^{c}$ Faculty of Engineering, Shizuoka University, 3-5-1 Johoku, Naka, Hamamatsu, Shizuoka 423-8561, Japan \\ ${ }^{\mathrm{d}}$ National Institute for Materials Science, 1-2-1 Sengen, Tsukuba, Ibaraki 305-0047, Japan \\ ${ }^{\mathrm{e}}$ Department of Mechanical Engineering, Tokyo University of Science, 2641 Yamazaki, Noda, Chiba 278-8510, Japan
}

Corresponding author at: Department of Space Flight System, Institute of Space and Astronautical Science (ISAS/JAXA), 3-1-1

Yoshinodai, Chuo, Sagamihara, Kanagawa 252-5210, Japan. Tel.: +81 (0)50-3362-7624; Fax: +81 (0)42-759-8532

E-mail addresses: tran.huunam@ac.jaxa.jp; namth@pvu.edu.vn (Tran Huu Nam)

\begin{abstract}
Drawing, winding, and pressing techniques were used to produce horizontally aligned carbon nanotube (CNT) sheets from free-standing vertically aligned CNT arrays. The aligned CNT sheets were used to develop aligned CNT/epoxy composites through hotmelt prepreg processing with a vacuum-assisted system. Effects of CNT diameter change on the mechanical properties of aligned CNT sheets and their composites were examined. The reduction of the CNT diameter considerably increased the mechanical properties of the aligned CNT sheets and their composites. The decrease of the CNT diameter along with pressing CNT sheets drastically enhanced the mechanical properties of the CNT sheets and CNT/epoxy composites. Raman spectra measurements showed improvement of the CNT alignment in the pressed CNT/epoxy composites. Research results suggest that aligned CNT/epoxy composites with high strength and stiffness are producible using aligned CNT sheets with smaller-diameter CNTs.
\end{abstract}

(C) 2015. This manuscript version is made available under the Elsevier user license http://www.elsevier.com/open-access/userlicense/1.0/ 
Keywords: A. Carbon nanotubes; A. Nano composites; B. Mechanical properties

\section{Introduction}

Since carbon nanotubes (CNTs) were discovered by Iijima in 1991 [1], they have attracted extensive research interest because of their extraordinary mechanical, electrical, and thermal properties [2-4]. Their exceptional mechanical properties along with their low density make CNTs an ideal choice for reinforcement of high-performance composite materials. However, most CNT composites have incorporated CNT powders dispersed in polymer matrices or deposited as thin films, which rely on unorganized CNT architectures having limited properties [5-7]. Therefore, recent studies related to CNTs have emphasized obtaining control of the engineering of organized architectures with determined orientations such as vertically aligned CNT arrays [8-10]. The organized CNT materials such as aligned CNT sheets can be produced from vertically aligned CNT arrays [11-13]. The easiest means of creating long-aligned CNT sheets from the CNT arrays is the use of a solid-state drawing technique [11]. This technique has been upgraded towards the goal of providing a continuous process for the solid-state fabrication of long-aligned and multi-ply CNT sheets $[12,13]$.

Highly aligned and multi-ply CNT sheets have been particularly promising as reinforcement for high-performance composite materials. Recently, composites based on aligned multi-ply CNT sheets have been developed using infiltrating, resin transfer molding, and hot-melt prepreg processing methods [14-17]. Although those composites contain aligned CNTs, their mechanical properties are low partly because of waviness and poor packing of CNTs in the composites. Therefore, mechanical stretching has been applied to reduce wavy and poorly packed CNTs, thereby improving the mechanical properties of aligned CNT-reinforced composites [18-21]. More recently, stretch- 
winding and resin spraying techniques have been applied to fabricate CNT-reinforced polymer composites with high strength and stiffness [22]. Most recently, a simple pressdrawing technique has been applied to produce superior aligned CNT sheets from CNT arrays for the development of aligned CNT-reinforced epoxy composites [23]. However, the strength and stiffness of such composites remain inadequate, probably because of large-diameter multi-walled CNTs.

The literature describes theoretical and experimental studies dedicated to the diameter-dependent elastic properties of CNTs [2,5]. The CNT diameter and the number of CNT walls have some noticeable effects on the elastic properties of multi-walled CNTs. For multi-walled CNTs, Inoue et al. [12] have described diameter-dependence on the strength and stiffness of multi-walled CNT sheets. The reduction of multi-walled CNT diameter has increased the effective cross-sectional area of testing samples, thereby improving CNT sheet strength and stiffness. The composite reinforced by thin CNTs with outer diameter of 7-9 $\mathrm{nm}$ has showed extremely high strength and stiffness [22]. In addition, Thostenson and Chou [24] reported that the properties of nanotubebased composites are affected strongly by the nanotube diameter. Nevertheless, studies of the influence of CNT diameter change on the mechanical properties of aligned CNTreinforced polymer composites are rare. Therefore, this study was conducted to examine the effects of CNT diameter change on the mechanical properties of aligned CNT sheets and CNT/epoxy composites. The non-pressed and pressed CNT sheets were used to develop corresponding aligned CNT/epoxy composites using hot-melt prepreg processing with a vacuum assisted system (VAS).

\section{Experimental}

\subsection{Materials}


Vertically aligned multi-walled CNT arrays with about $0.8 \mathrm{~mm}$ height were grown on quartz substrates using chloride-mediated chemical vapor deposition with single-gas flow of acetylene only, as presented by Inoue et al. [8]. As-grown multi-walled CNTs examined in this study have average diameters of $22 \mathrm{~nm}, 30 \mathrm{~nm}$ and $38 \mathrm{~nm}$, which are designated respectively as CNT-22, CNT-30 and CNT-38. Fig. 1 displays scanning transmission electron microscopy (STEM) images and histograms of diameter distribution for the different CNTs. Transmission electron microscopy images illustrating the high quality of CNTs have been presented in recent papers $[8,12]$. High crystal quality of the CNTs was also proven by Raman spectra measurements with a high intensity ratio between G-bands and D-bands [12]. The B-stage epoxy resin sheet covered with release paper and plastic film was obtained from Sanyu Rec. Co. Ltd. (Osaka, Japan) with the recommended cure condition of $130{ }^{\circ} \mathrm{C}$ for $2 \mathrm{~h}$. The areal weight of B-stage epoxy resin sheet with density of $1.2 \mathrm{~g} / \mathrm{cm}^{3}$ was controlled to approximately $12 \mathrm{~g} / \mathrm{m}^{2}$.

\subsection{Production of aligned CNT sheets}

The vertically aligned CNT arrays used for this study are self-oriented and highly drawable. Therefore, CNT webs were easily drawn from the vertically aligned CNT arrays and were wound on a rotating spool to produce a horizontally long-aligned CNT sheet (Fig. 2a). Detailed procedures for the CNT sheet processing by drawing and winding method have been reported elsewhere [12,17,20-23]. In addition, a top steel roll with transverse width of $30 \mathrm{~mm}$ and approximate mass of $450 \mathrm{~g}$ was used to press the CNT sheet (Fig. 2b). The pressing was applied directly where the CNT web enters the rotating spool to straighten wavy CNTs and to enhance the dense packing of CNTs in the sheets, as presented by Nam et al. [23]. The non-pressed and pressed 100-ply 
CNT sheets with average CNT diameters of $22 \mathrm{~nm}, 30 \mathrm{~nm}$ and $38 \mathrm{~nm}$ are designated respectively as NSX and PSX, where X corresponds to mean diameter of the CNTs in number (22, 30 and 38). The stacked 100-ply and 200-ply aligned CNT sheets were used for composite fabrication.

\subsection{Processing of aligned CNT/epoxy composites}

The aligned CNT-reinforced epoxy composites were developed using hot-melt prepreg processing with the VAS. This method maintains the alignment of CNTs during epoxy resin impregnation. The VAS was used during the composite fabrication to minimize air voids within the composites. First, an aligned CNT sheet with $20 \mathrm{~mm}$ width and $50 \mathrm{~mm}$ length was covered with an epoxy resin sheet and was set between two release films (WL5200; Airtech International Inc., CA, USA) to create an aligned CNT/epoxy prepreg. The prepreg was fabricated under $0.5 \mathrm{MPa}$ pressure for 5 min at $100^{\circ} \mathrm{C}$ using a test press (Model MP-WNL; Toyo Seiki Seisaku-sho Ltd., Tokyo, Japan). Subsequently, the prepreg was peeled off from the release paper and was placed on the VAS. Finally, the prepregs were cured at $130{ }^{\circ} \mathrm{C}$ for $2 \mathrm{~h}$ under $2 \mathrm{MPa}$ in the test press to produce aligned CNT/epoxy composites. A schematic representation of the VAS for the composite curing is depicted in Fig. 3.

\subsection{Thermogravimetric analysis (TGA)}

The thermal degradation processes of epoxy resin, the CNTs, and their composites were analyzed up to $800^{\circ} \mathrm{C}$ in argon ambient at a flow rate of $300 \mathrm{ml} / \mathrm{min}$ using a thermogravimetric analyzer (DTG-60A; Shimadzu Corp., Kyoto, Japan). About 5 mg of each specimen was loaded for each measurement at a heating rate of $10{ }^{\circ} \mathrm{C} / \mathrm{min}$.

\subsection{Characterizations and testing}


The properties of the CNT sheets and their composites were measured using conventional methods for macroscopic samples. Tensile tests were conducted for the CNT sheets and composites in a laboratory environment at room temperature (RT) of 23 $\pm 3{ }^{\circ} \mathrm{C}$ and $50 \pm 5 \%$ relative humidity. Tensile specimens with $6-10 \mathrm{~mm}$ gauge length and 3-5 mm width were tested on a testing machine (EZ-L; Shimadzu Corp., Kyoto, Japan) with a load cell of $50 \mathrm{~N}$ and a crosshead speed of $0.1 \mathrm{~mm} / \mathrm{min}$. Specimen widths were measured using an optical microscope (SZX12; Olympus Corp., Tokyo, Japan), whereas their thickness was measured using a micrometer with $0.001 \mathrm{~mm}$ accuracy (102-119; Mitutoyo Corp., Kanagawa, Japan). The thickness measurements using this micrometer were conducted carefully to minimize the measurement error. The strain of tensile specimens was measured using a non-contacting video extensometer (TRIViewX; Shimadzu Corp., Tokyo, Japan) with two targets. Mean tensile properties were obtained from at least five specimens for each CNT sheet and composite. Polarized Raman spectra were measured to ascertain the degree of CNT alignment in the composites using Raman spectroscope with laser excitation of $532 \mathrm{~nm}$ (XploRAONE; Horiba Ltd., Kyoto, Japan). The microstructural morphologies of CNTs in the sheets and fracture surfaces of the composites were observed using a field emission scanning electron microscope (FE-SEM, SU8030; Hitachi Ltd., Tokyo, Japan).

\section{Results and discussion}

\subsection{CNT volume fraction}

The air voids in the composites can be negligible because of using the VAS. Therefore, the CNT volume fraction was estimated using TGA data as follows: To begin with the respective mass losses of the CNTs, epoxy resin, and the composites were measured at 
$150-750^{\circ} \mathrm{C}$. Subsequently, the CNT mass fraction $\left(m_{f}\right)$ of CNTs in the composite was calculated from the mass loss of the CNTs $\left(\Delta m_{f}\right)$, epoxy resin $\left(\Delta m_{m}\right)$, and the composite $\left(\Delta m_{c}\right)$ as follows.

$m_{f}=\frac{\left(\Delta m_{m}-\Delta m_{c}\right)}{\left(\Delta m_{m}-\Delta m_{f}\right)}$

Finally, the CNT volume fraction $\left(V_{f}\right)$ was determined from the mass fraction of the CNTs, epoxy resin density $\left(\rho_{m}\right)$, and the density of the composite $\left(\rho_{c}\right)$ as follows.

$V_{f}=1-\frac{\left(1-m_{f}\right) \rho_{c}}{\rho_{m}}$

The mass losses, CNT mass fractions, and CNT volume fractions of the composites are presented in Table 1. As Table 1 shows, the CNT volume fraction in the composites with the same CNT plies reduces considerably with the decrease of the CNT diameter. This reduction is explainable by the fact that smaller diameter CNTs occupied a lower volume fraction in the composite than larger diameter CNTs do [24]. In addition, the pressing of the CNT sheets engendered a slight increase in the CNT mass fraction and the CNT volume fraction of the composites. The increase in the CNT volume fraction of the pressed composites is explained by the decrease of the composite thickness [23]. The reduction of the composite thickness is attributable to straightening of wavy CNTs and dense packing of CNTs in the sheets caused by the pressing (see Fig. 4).

\subsection{Properties and morphologies of aligned CNT sheets and composites}

The mechanical properties of epoxy resin, aligned CNT sheets, and CNT/epoxy composites were measured using tensile tests. The epoxy resin showed average tensile strength of $64.4 \mathrm{MPa}$, elastic modulus of $2.6 \mathrm{GPa}$, and fracture strain of $4.8 \%$. The properties of the non-pressed and pressed 100-ply CNT sheets are presented in Table 2. 
FE-SEM micrographs of the non-pressed and pressed 100-ply CNT sheets are displayed in Fig. 4. As Table 2 shows, the thickness and areal weight of the CNT sheets with the same number of CNT plies decrease slightly with decreasing CNT diameter. In addition, the thickness and areal weight of the pressed CNT sheets are less than those of the nonpressed ones. The decreased areal weight of the CNT sheets is attributed to a slight reduction of their weight after pressing process. The reduced thickness of the pressed CNT sheets can be attributed to the straightening of wavy CNTs and increasing of the dense packing of CNTs in the sheets, as described above (see Fig. 4). When the CNT sheets are pressed, the CNTs are compacted in the pressing direction with less interspace between CNTs [23]. Consequently, the pressed CNT sheet thickness became less than that of the non-pressed ones.

Typical stress-strain curves of aligned CNT sheets and CNT/epoxy composites are depicted in Fig. 5. As observed in Fig. 5, the stress-strain curve of the NS38 is divisible into three main stages. In the first stage, the stress of the NS38 is enhanced evenly with increasing strain to about $1.5 \%$. Subsequently, the stress varies slightly up to the maximum with increasing strain to approximately $3.5 \%$ in the second stage. In the first and second stages, the wavy CNTs may be straightened under the tension. The third stage occurs above about $3.5 \%$ strain. In this stage, the stress declines concomitantly with enhancing strain up to the specimen fractures. Reduction of the stress in the third stage is attributed to CNT sliding during tensile testing [12]. Unlike the NS38, the stress of NS22 and NS30 is enhanced gradually up to the maximum when the strain increases to about $2.5 \%$. Subsequently, it decreases concomitantly to about $5 \%$ strain and slowly decreases thereafter until the specimen fractures. To approximate the stress-strain behavior of the NS22 and NS30, the stress of the pressed CNT sheets is enhanced 
rapidly with the increase of the strain to less than $1 \%$. Afterward it declines quickly to about $1.5 \%$ strain, followed by a slow decrease until the sample fractures.

Unlike the CNT sheets, the aligned CNT/epoxy composites indicated a linear stressstrain relation until the sample fracture with no bending of the curve at high loads (see Fig. 5). The composites all broke in a brittle manner during tensile testing, with no permanent change in the original shape. Tensile strength and elastic modulus of the nonpressed and pressed 100-ply and 200-ply CNT/epoxy composites with mean diameters of $22 \mathrm{~nm}, 30 \mathrm{~nm}$ and $38 \mathrm{~nm}$ are presented in Fig. 6. Average fracture strain of the composites was $0.39-0.53 \%$. FE-SEM micrographs showing the in-plane CNT distribution in non-pressed and pressed composites are presented in Fig. 7. Results show that aligned CNT reinforcement greatly enhanced tensile strength and elastic modulus of epoxy resin. The increase in tensile strength and elastic modulus is attributed to the reinforcement of aligned CNTs along the tensile direction. When CNTs are aligned in the loading direction, excellent mechanical properties of CNTs, having a cylindrical structure, might be used effectively [23]. The aligned CNTs carry the load along the length of CNTs and provide strength and stiffness in the loading direction. As Fig. 4 shows, most CNTs in the sheets are self-aligned in the drawing direction. The alignment of CNTs in the composites is maintained during resin impregnation using hot-melt prepreg processing (see Fig. 7). The non-pressed CNT/epoxy composites contained many wavy and entangled CNTs (Figs. 7a,7c,7e). The pressed CNT/epoxy composite showed marked straightening of wavy CNTs caused by pressing the CNT sheets (Figs. $7 b, 7 d, 7 f)$.

The straightening and alignment of CNTs after pressing can be examined using polarized Raman spectroscopy $[25,26]$. Typical polarized Raman spectra in the range of 
$1000-2000 \mathrm{~cm}^{-1}$ are presented in Fig. 8. Raman spectroscopic measurements were conducted with incident light normal to the composite samples, which was polarized parallel and perpendicular to the CNT alignment (see the Fig. 8 inset). Raman spectra for all samples show two main peaks located at approximately $1350 \mathrm{~cm}^{-1}$ and approx. $1580 \mathrm{~cm}^{-1}$, which are attributed respectively to the disorder-induced D band and the graphic-like G band. Results show that the Raman shift does not change considerably for the variation of mean $\mathrm{CNT}$ diameter from $22 \mathrm{~nm}$ to $38 \mathrm{~nm}$. Compared with the nonpressed samples, the pressed ones showed a higher intensity of $\mathrm{D}$ and $\mathrm{G}$ bands at $0^{\circ}$ and lower $\mathrm{D}$ and $\mathrm{G}$ band peaks at $90^{\circ}$. Particularly, the $\mathrm{G}$ band peaks decreased greatly for the pressed composites at the angle of $90^{\circ}$, which proves that the CNT alignment in the composites was improved considerably after pressing the CNT sheets.

Furthermore, the changes of the intensity ratio between the G-bands and D-bands $\left(I_{\mathrm{G}} / I_{\mathrm{D}}\right)$ and the G-band intensity ratio for the two polarizations $\left(R=I_{G \|} / I_{G \perp}\right)$ are presented in Table 3 . The high intensity ratio $I_{\mathrm{G}} / I_{\mathrm{D}}$ indicates high crystal quality of CNTs and low amount of amorphous carbon, similarly to that presented by Inoue et al. [12]. In addition, the intensity ratio $I_{\mathrm{G}} / I_{\mathrm{D}}$ increases concomitantly with increasing $\mathrm{CNT}$ diameter. Singh et al. [27] showed that the enhancement of CNT diameter, as the number of graphene layers increases, led to the reduction in the D-band intensity. The G-band intensity ratio is widely used for characterizing the degree of CNT alignment $[12,25-27]$. The G-band intensity ratio of the pressed composite samples is markedly higher than that of the non-pressed ones (see Table 3). The enhancement in R can be ascribed to the better alignment of CNTs in the pressed CNT/epoxy composites compared with the non-pressed ones. However, the G-band intensity of the non-pressed and pressed composites does not change greatly with variation of the CNT diameter. 
Consequently, the change of CNT diameter only slightly influences the alignment of CNTs and straightening of wavy CNTs caused by pressing.

Fracture surfaces of the non-pressed and pressed CNT/epoxy composites are shown in the FE-SEM micrographs presented in Fig. 9. High-resolution micrographs in Fig. 9 show that epoxy resin was infiltrated well between the CNTs. Many pulled-out CNTs with length of a few micrometers are exposed on the fracture surfaces of the nonpressed CNT/epoxy specimens (Figs. 9a,9c,9e). However, several pulled-out CNTs apparently disappeared on the fracture surfaces of the pressed CNT/epoxy composites (Figs. 9b,9d,9f). Simultaneously, CNT bundles formed by pressing are visible on the fracture surfaces of the pressed CNT/epoxy composites. The CNT bundles caused by pressing are apparent on the surface morphologies of the pressed CNT sheets (Figs. $4 \mathrm{~b}, 4 \mathrm{~d}, 4 \mathrm{f})$.

\subsection{Effects of CNT diameter on mechanical properties of CNT sheets and composites}

As Table 2 shows, tensile strength and elastic modulus of the CNT sheets are increased with decreasing CNT diameter. The NS30 and PS30 respectively exhibited increased tensile strength by $84 \%$ and $55 \%$, and enhanced elastic modulus by $54 \%$ and $17 \%$ compared with the NS40 and PS40. The increase in the tensile strength and elastic modulus is partly due to the decrease of CNT sheet thickness (see Table 1). In addition, the enhancement in the tensile strength can be attributed to the increase of effective cross-sectional area of the CNT sheets as the CNT diameter decreases [12]. However, the tensile strength and elastic modulus of the CNT sheets increase only slightly with the reduction of mean-diameter CNTs from $30 \mathrm{~nm}$ to $22 \mathrm{~nm}$. The slight increase of the tensile strength and elastic modulus is attributable to an inconsiderable change of the CNT sheet thickness. 
As with the CNT sheets, tensile strength and elastic modulus of the non-pressed and pressed CNT/epoxy composites are enhanced with the decrease of CNT diameter (see Fig. 6). For example, the pressed 200-ply CNT/epoxy composite with average CNT diameter of $22 \mathrm{~nm}$ showed tensile strength enhancement of $12 \%$ and elastic modulus increase of $14 \%$ compared to that of CNTs with mean diameter of $38 \mathrm{~nm}$. Thostenson and Chou [24] reported that elastic properties of CNT-based composites are particularly sensitive to the CNT diameter because larger diameter CNTs showed a lower effective modulus and occupy a greater volume fraction in the composite than smaller diameter CNTs do. Moreover, several reports have described that the bonding between the walls of the multi-walled nanotube through van der Waals interactions is weak, resulting in minimal load transfer between the layers of the nanotube [24,29-31]. Therefore, the outermost walls of the multi-walled nanotube carry almost the entire load transferred at the nanotube/matrix interface. The large-diameter multi-walled CNTs in the composites may fracture via the sword-and-sheath mechanism [17], which implies that inner walls slide and do not carry much load. All these facts imply that the strength and stiffness of multi-walled CNT-based composites are enhanced as the CNT diameter decreases.

It is particularly interesting that with the same number of CNT plies, the pressed composites showed greater mechanical properties than those of the non-pressed ones, although the CNT diameter was reduced (see Fig. 6). For instance, the pressed 200-ply CNT/epoxy composites with average CNT diameter of $38 \mathrm{~nm}$ exhibited an increase in tensile strength by $47 \%$, in elastic modulus by $39 \%$, and in fracture strain by $6 \%$ compared to the non-pressed ones with mean CNT diameter of $22 \mathrm{~nm}$. The increase in the mechanical properties of the pressed composites is explainable by the substantial reduction of wavy CNTs (see Fig. 7) and enhancing the dense packing of CNTs in the 
sheets caused by pressing [23]. To evaluate the effect of pressing and CNT diameter decrease, the percentage increase of the mean elastic modulus of the pressed composites compared with that of the non-pressed ones was analyzed, with results presented in Fig. 10. The percentage increase in the elastic modulus of the composites varies slightly with the change of CNT diameter. The large-diameter CNT showed a slight reduction in the percent increase of elastic modulus compared with small-diameter CNT. Therefore, the CNT diameter variation does not strongly affect the quality and alignment of CNTs in the composites as well as straightening of wavy CNTs caused by pressing, as explained above. However, the percentage increase in the elastic modulus of the 200-ply CNT/epoxy composites is lower than that of the 100-ply ones. This reduction might be attributed to decreased effectiveness of pressing when increasing the CNT volume fraction. Therefore, the percentage increase of elastic modulus caused by pressing shows a reduced trend with enhancement of the CNT volume fraction, which is similar to that which arises from stretching [21].

Tensile strength and elastic modulus of the non-pressed and pressed CNT/epoxy composites with different CNT diameters can be studied as a function of the CNT volume fraction. With the same mean CNT diameter, the tensile strength and elastic modulus of the composites increases considerably as the CNT volume fraction is enhanced (see Fig. 6). As presented above, the length of the different CNTs used for this study is about $0.8 \mathrm{~mm}$. The aspect ratio (length to diameter ratio) of the CNTs is extremely high $(>10,000)$. Therefore, the elastic modulus of the aligned CNT/epoxy composites might be estimated using the rule of mixtures [17]. The effective elastic modulus of a CNT in the composites was estimated using the following equation.

$$
E_{C N T}=\frac{E_{c}-\left(1-V_{f}\right) E_{m}}{V_{f}}
$$


Therein, $E_{c}$ and $E_{m}$ respectively are elastic modulus of the composite and epoxy matrix.

The effective elastic modulus of a CNT in the composites having different numbers of CNT plies is presented in Fig. 11. The best fit effective elastic modulus of a CNT was found to be from about 150 to $220 \mathrm{GPa}$ for the non-pressed composites and from about 200 to $380 \mathrm{GPa}$ for the pressed composites. The higher effective elastic modulus of a CNT in the pressed composites is attributed to the higher CNT alignment caused by pressing compared with the non-pressed composites. As might be inferred from Fig. 11, the effective elastic modulus of CNT as a function of diameter was enhanced considerably by reduction of the CNT diameter. The increase in the effective elastic modulus of CNT is attributed to the reduction of CNT loading and to the enhancement of the elastic modulus of the composites (Fig. 6). Treacy et al. [3] showed that the elastic modulus is highest for the thinner nanotubes. They suggested a trend by which higher moduli are associated with smaller tube thicknesses. In addition, the multi-walled CNTs used for this study consist of several concentric walls. Their outer diameter is large (> $20 \mathrm{~nm})$. Those CNTs can render wall slippage in the multi-walled CNT structure [12]. The larger diameter CNTs with greater wall numbers exhibited a lower effective modulus because of wall slippage [32]. Therefore, it was recognized that the reduction of CNT diameter engenders enhancement of the effective elastic modulus of CNTs.

In general, the decrease of CNT diameter together with pressing of the CNT sheets drastically improved the mechanical properties of the CNT/epoxy composites. The pressed 100-ply and 200-ply CNT/epoxy composites with mean CNT diameter of 22 $\mathrm{nm}$ respectively exhibited a substantial increase in tensile strength by $157 \%$ and $95 \%$ and in the elastic modulus by $79 \%$ and $67 \%$ compared to the non-pressed ones with 
average CNT diameter of $38 \mathrm{~nm}$. Results show that the CNT diameter reduction plays an important role in improving the strength and stiffness of the CNT composites. The mean tensile strength and elastic modulus of the aligned CNT/epoxy composites in this study were achieved as high as $676 \mathrm{MPa}$ and $130 \mathrm{GPa}$, respectively, which were 10.5 and 50.9 times greater than those of the epoxy resin.

\section{Conclusions}

Effects of CNT diameter on the mechanical properties of the non-pressed and pressed aligned CNT sheets and CNT/epoxy composites have been studied. The reduction of CNT diameter has caused considerable enhancement in the mechanical properties of the aligned CNT sheets and CNT/epoxy composites. The change of CNT diameter did not strongly affect the CNT alignment and or straightening of wavy CNTs caused by pressing of the CNT sheets. The decrease of CNT diameter along with pressing of the CNT sheets greatly improved the mechanical properties of the aligned CNT sheets and their composites. Raman spectra measurements indicated the improvement of CNT alignment in the pressed CNT/epoxy composites. The Raman shift did not change considerably for the variation of CNT diameter. Overall, experimentally obtained results suggest that high strength and stiffness of the aligned CNT/epoxy composites can be achieved if using the pressed aligned CNT sheets with smaller-diameter CNTs.

\section{Acknowledgements}

We appreciate financial support from the Japan Science and Technology Agency (JST) through the Advanced Low Carbon Technology Research and Development Program (ALCA) and the Institute of Space and Astronautical Science (ISAS) through the ISAS strategic development fund for space engineering. 


\section{References}

[1] Iijima S. Helical microtubules of graphitic carbon. Nature 1991;354(6348):56-8.

[2] Ruoff RS, Lorents DC. Mechanical and thermal properties of carbon nanotubes. Carbon 1995;33(7):925-30.

[3] Treacy MMJ, Ebbesen TW, Gibson JM. Exceptionally high Young's modulus observed for individual carbon nanotubes. Nature 1996;381:678-80.

[4] Ebbesen TW, Lezec HJ, Hiura H, Bennett JW, Ghaemi HF, Thio T. Electrical conductivity of individual carbon nanotubes. Nature 1996;382:54-6.

[5] Thostenson ET, Ren Z, Chou TW. Advances in the science and technology of carbon nanotubes and their composites: a review. Compos Sci Technol 2001;61(13):1899-912.

[6] Coleman JN, Khan U, Blau WJ, Gun'ko YK. Small but strong: a review of the mechanical properties of carbon nanotube-polymer composites. Carbon 2006;44(9):1624-52.

[7] De Volder MFL, Tawfick SH, Baughman RH, Hart AJ. Carbon nanotubes: Present and future commercial applications. Science 2013;339(6119):535-9.

[8] Inoue Y, Kakihata K, Hirono Y, Horie T, Ishida A, Mimura H. One-step grown aligned bulk carbon nanotubes by chloride mediated chemical vapor deposition. Appl Phys Lett 2008;92(21):213113.

[9] Lepro X, Lima MD, Baughman RH. Spinnable carbon nanotubes forests grown on thin, flexible metallic substrates. Carbon 2010;48(12):3621-7.

[10] Patole SP, Kim H-I, Jung J-H, Patole AS, Kim H-J, Han I-T, et al. The synthesis of vertically-aligned carbon nanotubes on an aluminum foil laminated on stainless steel. Carbon 2011;49(11):3522-8. 
[11]Zhang M, Fang S, Zakhidov AA, Lee SB, Aliev AE, Williams CD, et al. Strong, transparent, multifunctional, carbon nanotube sheets. Science 2005;309(5738):1215-9.

[12] Inoue Y, Suzuki Y, Minami Y, Muramatsu J, Shimamura Y, Suzuki K, et al. Anisotropic carbon nanotube papers fabricated from multiwalled carbon nanotube webs. Carbon 2011;49(7):2437-43.

[13]Pöhls JH, Johnson MB, White MA, Malik R, Ruff B, Jayasinghe C, et al. Physical properties of carbon nanotube sheets drawn from nanotube arrays. Carbon 2012;50(11):4175-83.

[14]Cheng QF, Wang JP, Jiang KL, Li QQ, Fan SS. Fabrication and properties of aligned multiwalled carbon nanotube-reinforced epoxy composites. J Mater Res 2008;23(11):2975-83.

[15]Cheng QF, Wang JP, Wen JJ, Liu CH, Jiang KL, Li QQ, et al. Carbon nanotube/epoxy composites fabricated by resin transfer molding. Carbon 2010;48(1):260-6.

[16]Bradford PD, Wang X, Zhao H, Maria JP, Jia Q, Zhu YT. A novel approach to fabricate high volume fraction nanocomposites with long aligned carbon nanotubes. Compos Sci Technol 2010;70(13):1980-5.

[17] Ogasawara T, Moon SY, Inoue Y, Shimamura Y. Mechanical properties of aligned multi-walled carbon nanotube/epoxy composites processed using a hot-melt prepreg method. Compos Sci Technol 2011;71(16):1826-33.

[18]Cheng QF, Bao J, Park J, Liang Z, Zhang C, Wang B. High mechanical performance composite conductor: multi-walled carbon nanotube sheet/bismaleimide nanocomposites. Adv Funct Mater 2009;19(20):3219-25. 
[19]Li S, Park JG, Liang Z, Siegrist T, Liu T, Zhang M, et al. In situ characterization of structural changes and the fraction of aligned carbon nanotube networks produced by stretching. Carbon 2012;50(10):3859-67.

[20]Wang X, Bradford PD, Liu W, Zhao H, Inoue Y, Maria JP, et al. Mechanical and electrical property improvement in CNT/Nylon composites through drawing and stretching. Compos Sci Technol 2011;71(14):1677-83.

[21] Nam TH, Goto K, Oshima K, Premalal V, Shimamura Y, Inoue Y, et al. Effects of stretching on mechanical properties of aligned multi-walled carbon nanotube/epoxy composites. Composites Part A 2014;64:194-202.

[22] Wang Z, Yong ZZ, Li QW, Bradford PD, Liu W, Tucker DS, et al. Ultrastrong, stiff and multifunctional carbon nanotube composites. Mater Res Lett 2013;1:1925.

[23] Nam TH, Goto K, Oshima K, Premalal V, Shimamura Y, Inoue Y, et al. Mechanical property enhancement of aligned multi-walled carbon nanotube sheets and composites through press-drawing process. Adv Comp Mater 2014, article in press. http://dx.doi.org/10.1080/09243046.2014.985419.

[24] Thostenson ET, Chou TW. On the elastic properties of carbon nanotube-based composites: modelling and characterization. J Phys D 2003;36(5):573.

[25] Ji J, Sui G, Yu Y, Liu Y, Lin Y, Du Z, et al. Significant improvement of mechanical properties observed in highly aligned carbon-nanotube-reinforced nanofibers. J Phys Chem C 2009;113(12):4779-85.

[26]Liu W, Zhang X, Xu G, Bradford PD, Wang X, Zhao H, et al. Producing superior composites by winding carbon nanotubes onto a mandrel under a poly(vinyl alcohol) spray. Carbon 2011;49(14):4786-91. 
[27] Singh DK, Iyer PK, Giri PK. Diameter dependence of interwall separation and strain in multiwalled carbon nanotubes probed by X-ray diffraction and Raman scattering studies. Diam Relat Mater 2010;19(10):1281-8.

[28]Fischer JE, Zhou W, Vavro J, Llaguno MC, Guthy C, Haggenmueller R, et al.

Magnetically aligned single wall carbon nanotube films: Preferred orientation and anisotropic transport properties. J App Phys 2003;93(4):2157-63.

[29] Schadler LS, Giannaris SC, Ajayan PM. Load transfer in carbon nanotube epoxy composites. Appl Phys Lett 1998;73(26):3842-4.

[30] Li C and Chou TW. Elastic moduli of multi-walled carbon nanotubes and the effect of van der Waals forces. Compos Sci Technol 2003;63(11):1517-24.

[31] Gojny F, Wichmann M, Fiedler B, Schulte K. Influence of different carbon nanotubes on the mechanical properties of epoxy matrix composites - a comparative study. Compos Sci Technol 2006;65(15):2300-13.

[32] Wang X, Jiang Q, Xu W, Cai W, Inoue Y, Zhu Y. Effect of carbon nanotube length on thermal, electrical and mechanical properties of CNT/bismaleimide composites. Carbon 2013;53:145-52. 
Fig. 1 - STEM images and histograms of diameter distribution for the CNTs with mean diameters of: (a) $22 \mathrm{~nm}$; (b) $30 \mathrm{~nm}$, and (c) $38 \mathrm{~nm}$.

Fig. 2 - Schematics showing aligned CNT sheet processing: (a) drawing and winding; (b) drawing, winding, and pressing.

Fig. 3 - Schematic showing a vacuum-assisted system for composite curing.

Fig. 4 - FE-SEM micrographs exhibiting the morphologies of (a,c,e) non-pressed and (b,d,f) pressed CNT sheets with mean CNT diameter of (a,b) $22 \mathrm{~nm},(\mathrm{c}, \mathrm{d}) 30 \mathrm{~nm}$ and (e,f) $38 \mathrm{~nm}$.

Fig. 5 - Typical stress-strain curves of aligned CNT sheets and a 200-ply CNT-30 reinforced epoxy composite. Note that the typical stress-strain curves of the NS38 and PS38 were referred from our earlier report [23].

Fig. 6 - Tensile strength and elastic modulus of non-pressed (hollow markers) and pressed (solid markers) composites reinforced by 100-ply and 200-ply CNT sheets with mean CNT diameter of 22nm, $30 \mathrm{~nm}$ and $38 \mathrm{~nm}$. *Results were referred from our earlier report [23].

Fig. 7 - FE-SEM micrographs showing in-plane CNT distribution of (a,c,e) non-pressed and (b,d,f) pressed 200-ply CNT/epoxy composites with mean CNT diameter of (a,b) 22 nm, (c,d) $30 \mathrm{~nm}$ and (e,f) $38 \mathrm{~nm}$.

Fig. 8 - Polarized Raman spectra of non-pressed and pressed 200-ply CNT/epoxy composites with mean CNT diameter of $22 \mathrm{~nm}, 30 \mathrm{~nm}$ and $38 \mathrm{~nm}$ at $0^{\circ}$ and $90^{\circ}\left(0^{\circ}\right.$ and $90^{\circ}$ directions correspond to configurations where the polarization direction of the laser light are, respectively, parallel and perpendicular to the direction of CNT alignment). 
Fig. 9 - FE-SEM micrographs showing fracture surfaces of (a,c,e) non-pressed and (b,d,f) pressed 100-ply CNT/epoxy composites with mean CNT diameter of (a,b) 22 nm, (c,d) $30 \mathrm{~nm}$ and (e,f) $38 \mathrm{~nm}$.

Fig. 10 - Percentage increases of elastic moduli in comparison between the pressed composites and non-pressed composites.

Fig. 11 - Effective elastic moduli of CNTs estimated from the rule of mixtures. 

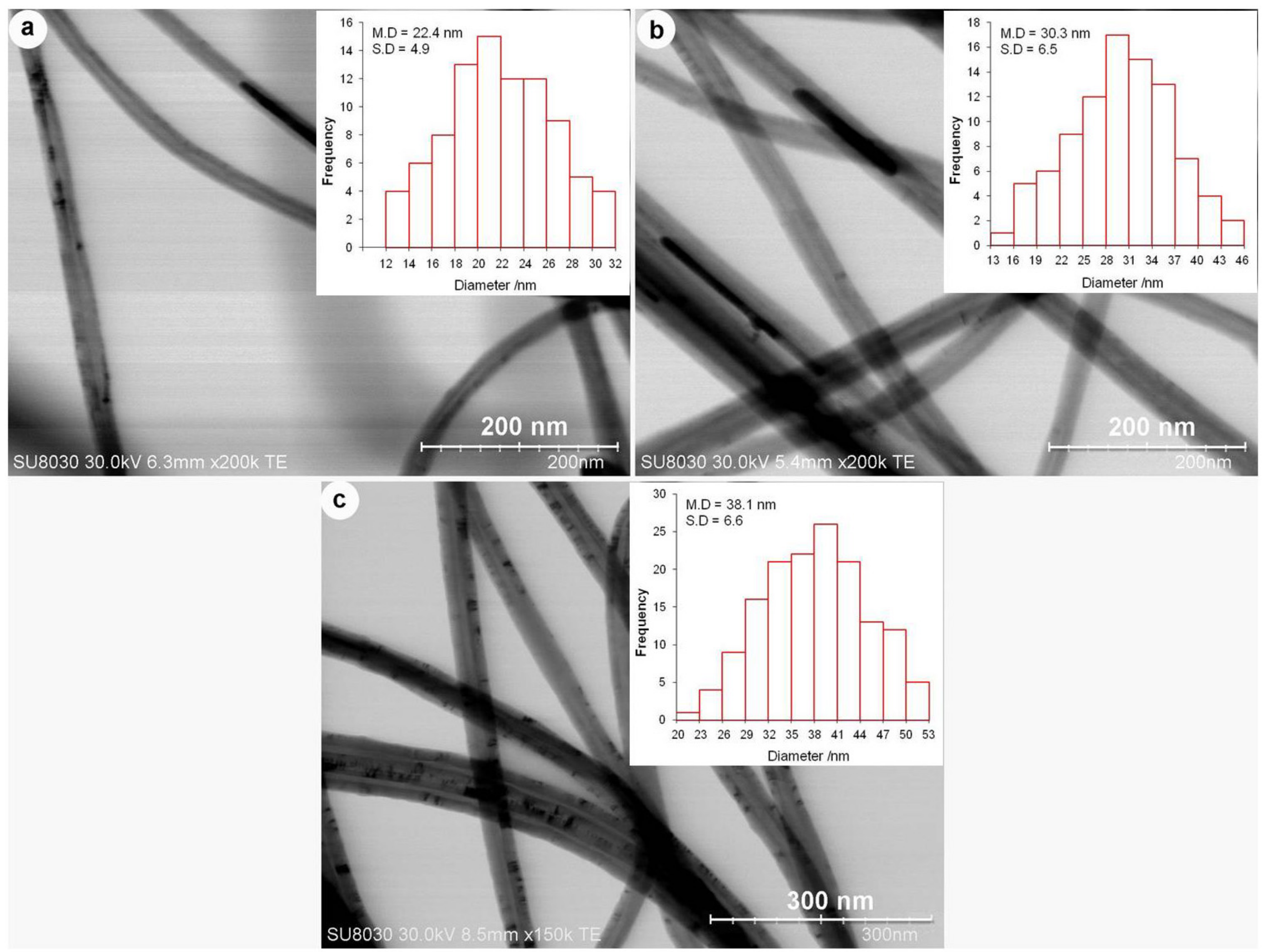
Figure 2

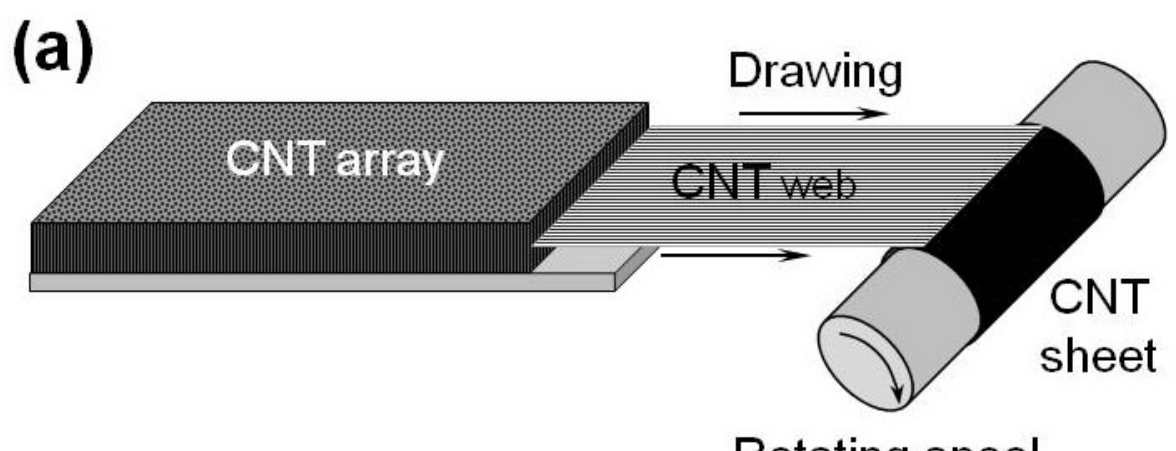

Rotating spool

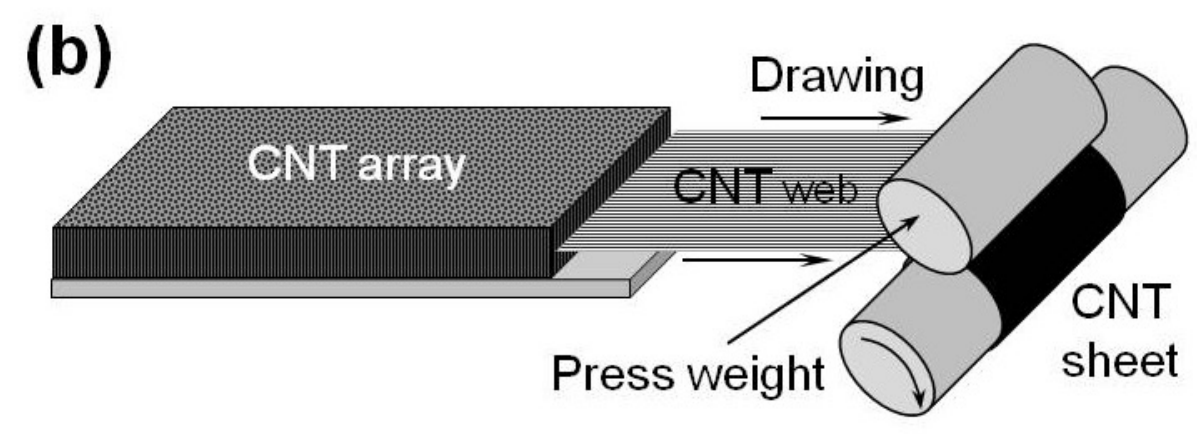

Rotating spool 


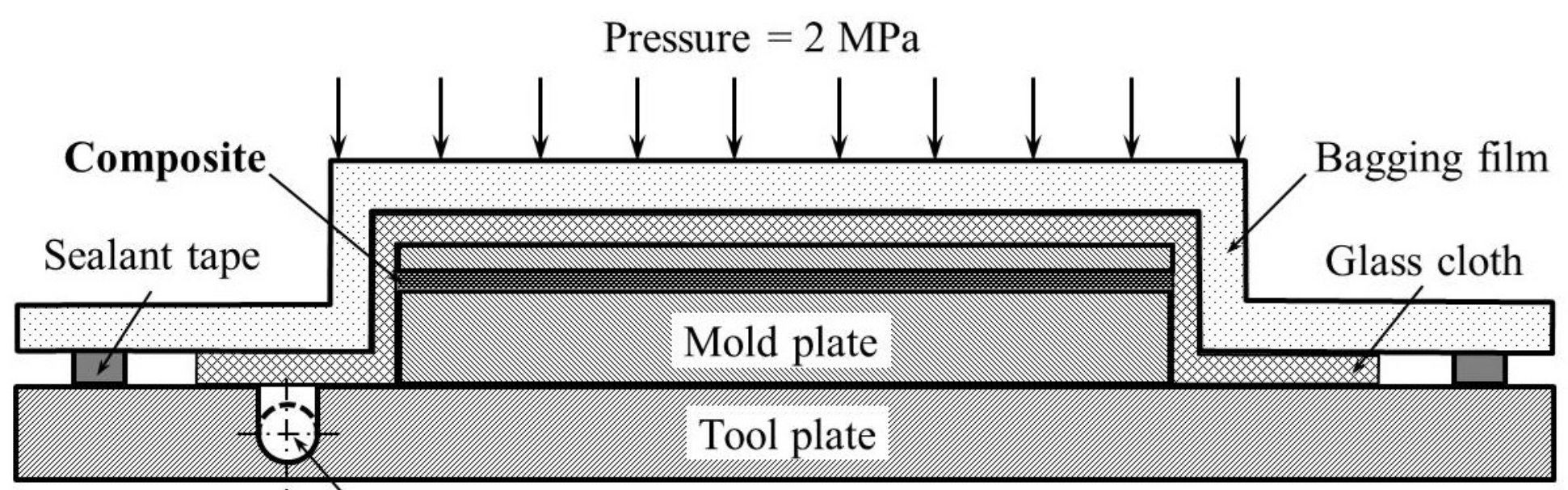

Vacuum port 

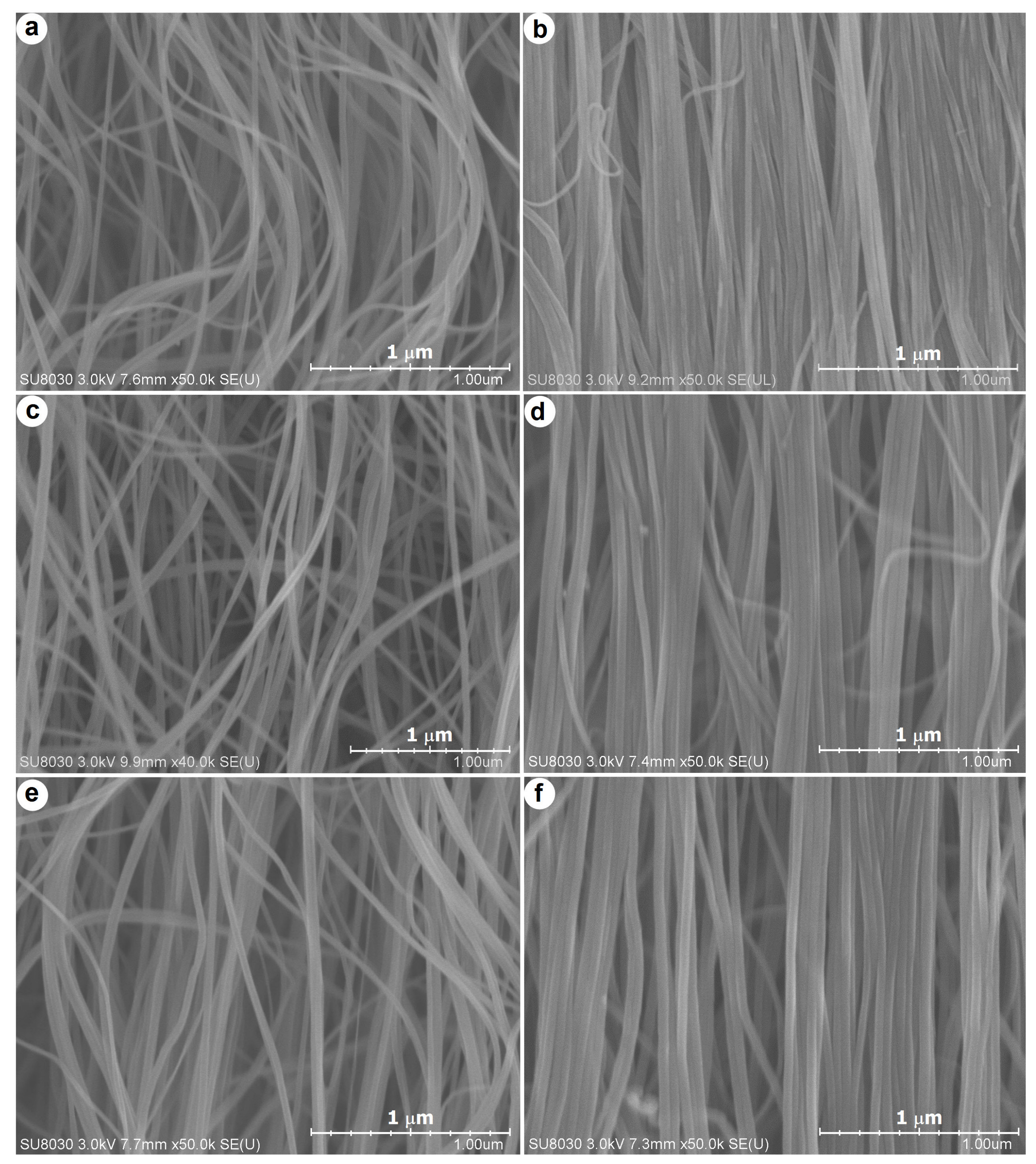

Figure 4 
Figure 5

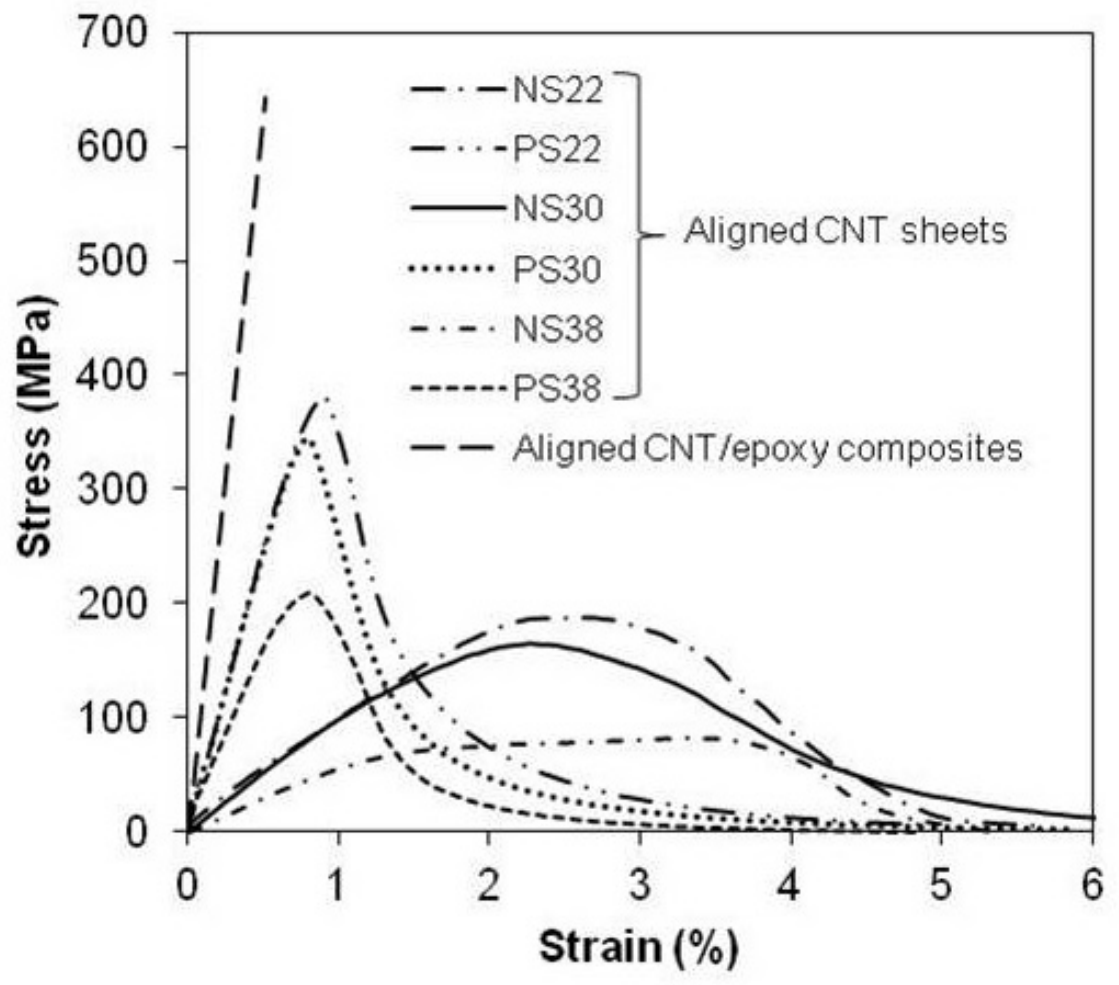


Figure 6
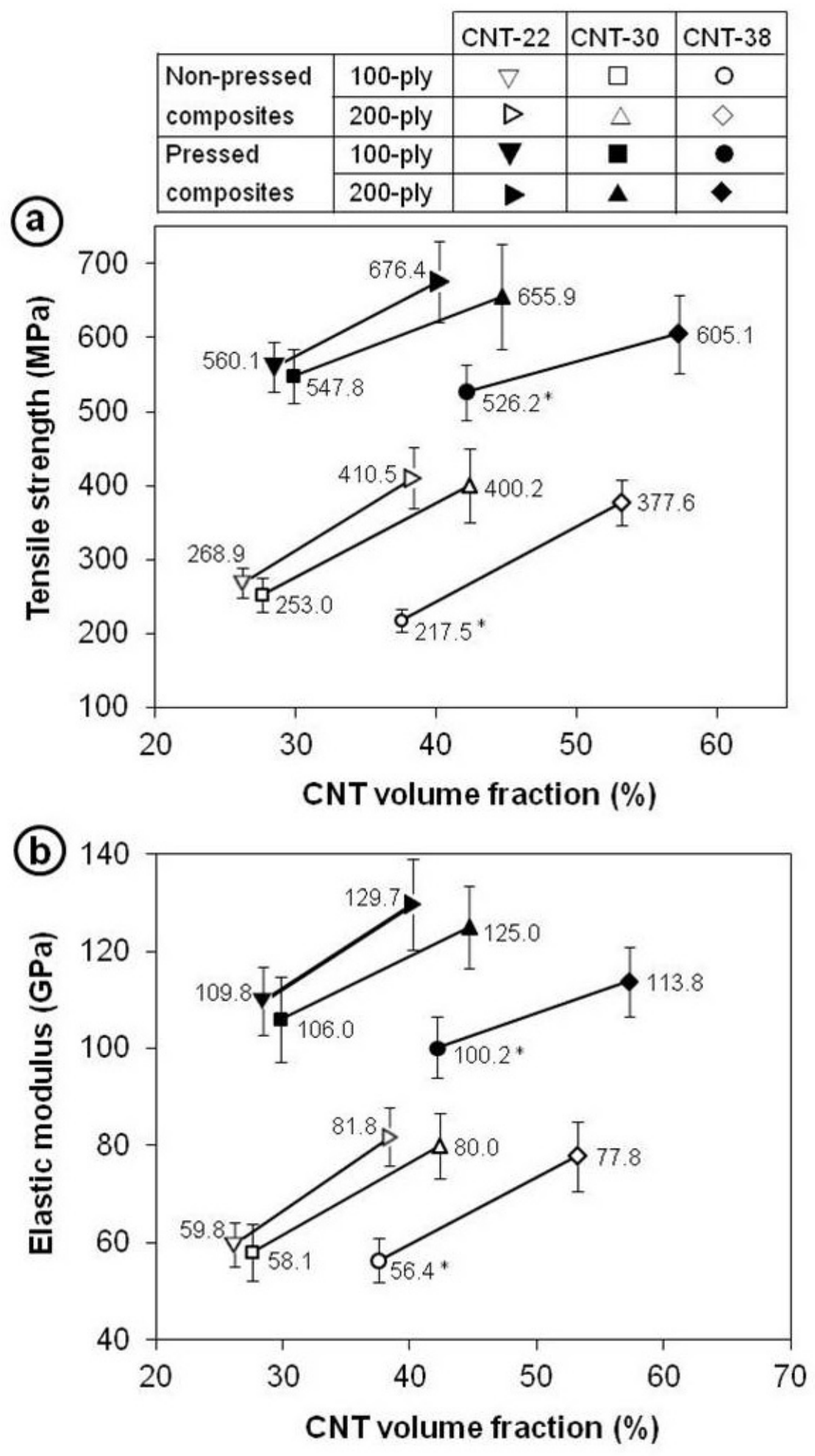
Figure 7

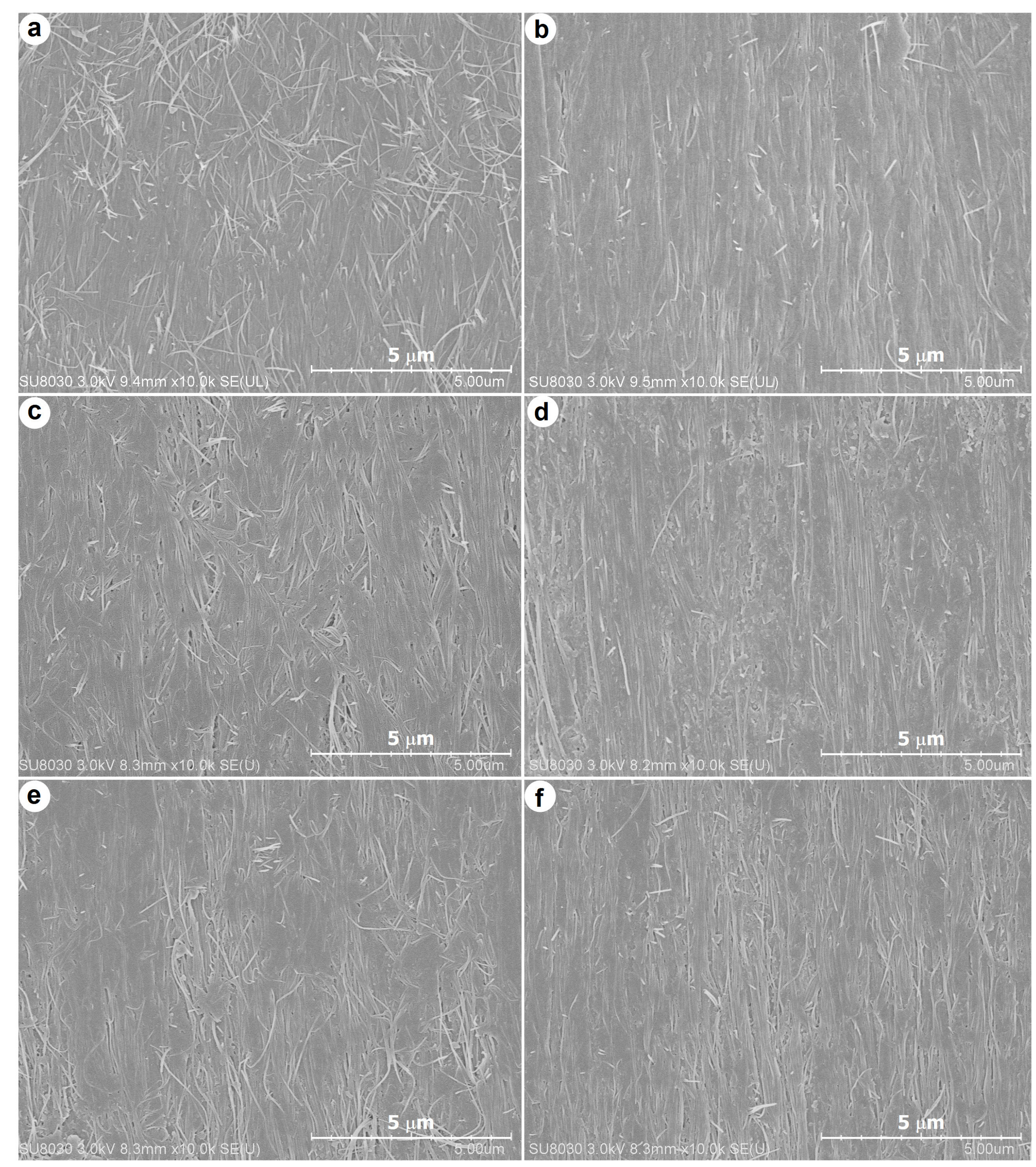

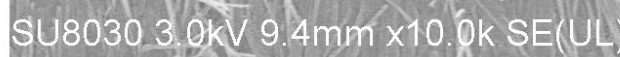

d). 

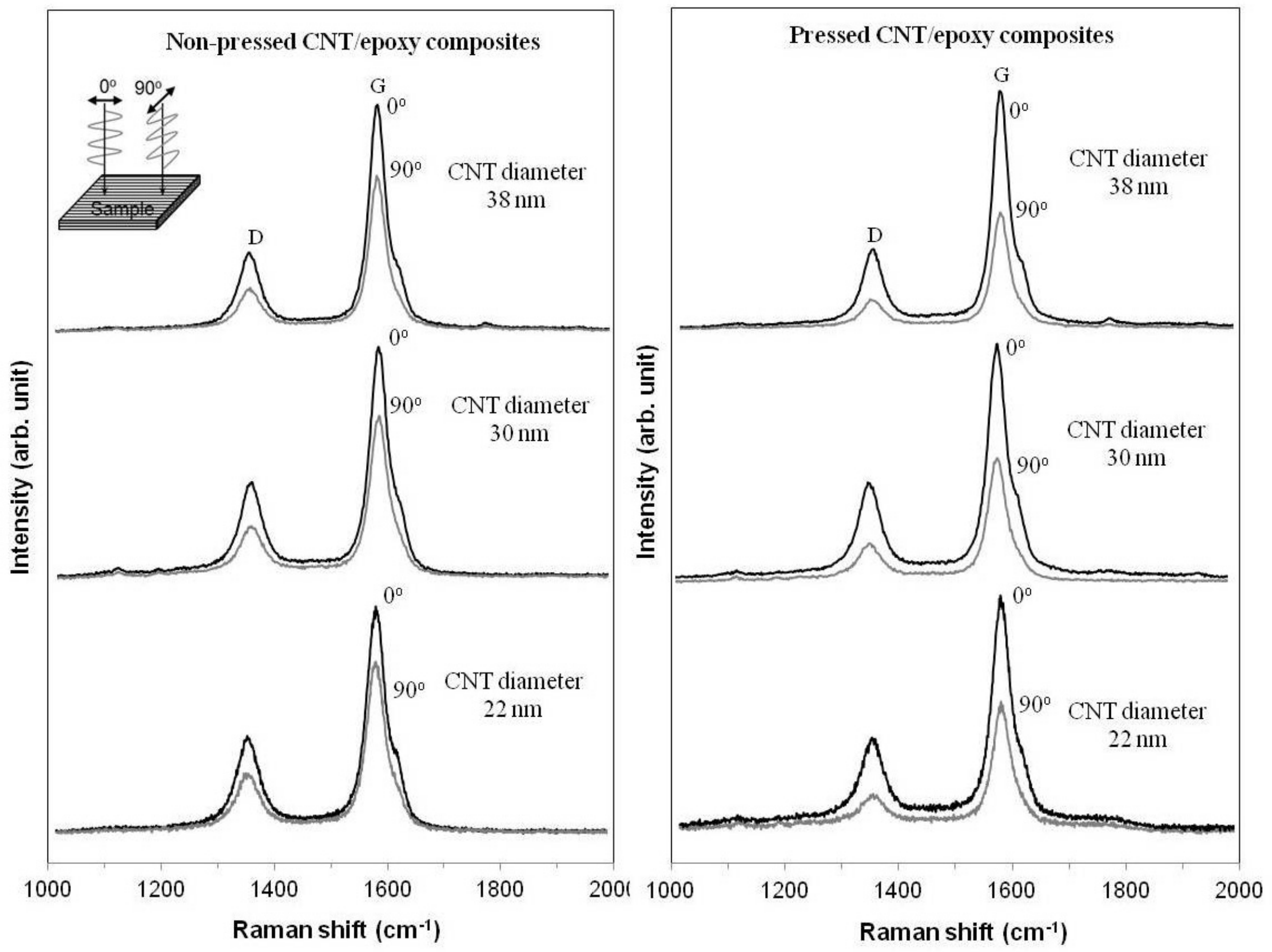


\section{Figure 9}
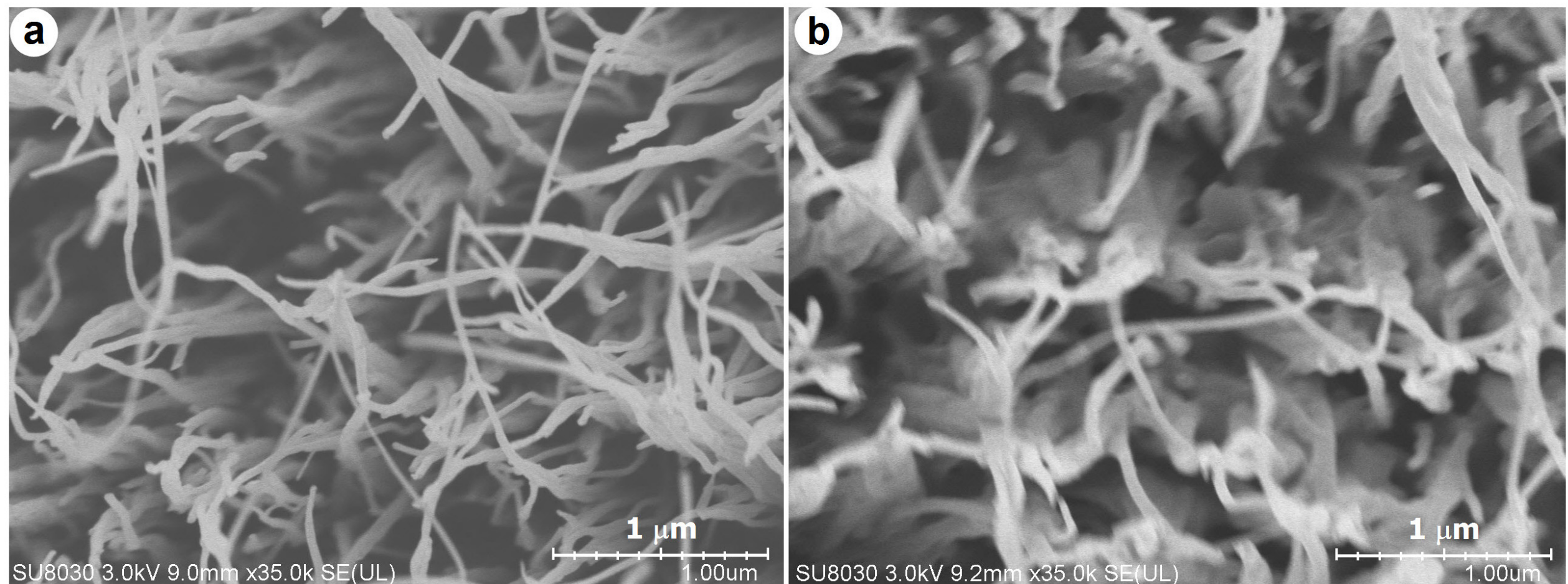

$\frac{(2)}{\sqrt{2}}$

$6(1)+5$

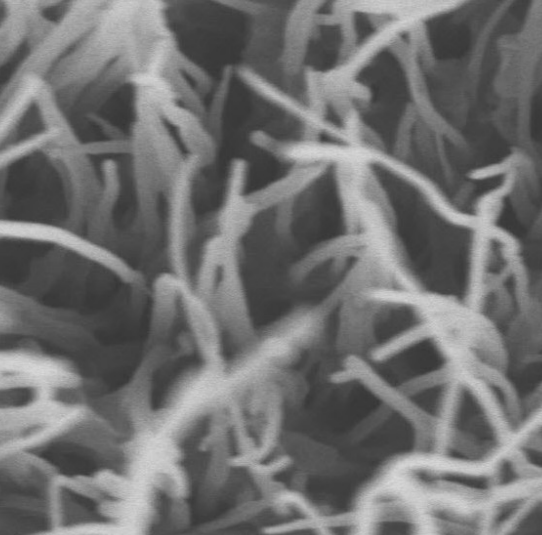

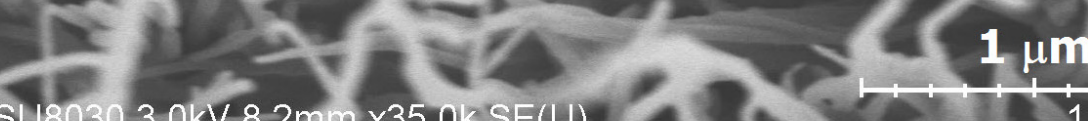

\section{-}

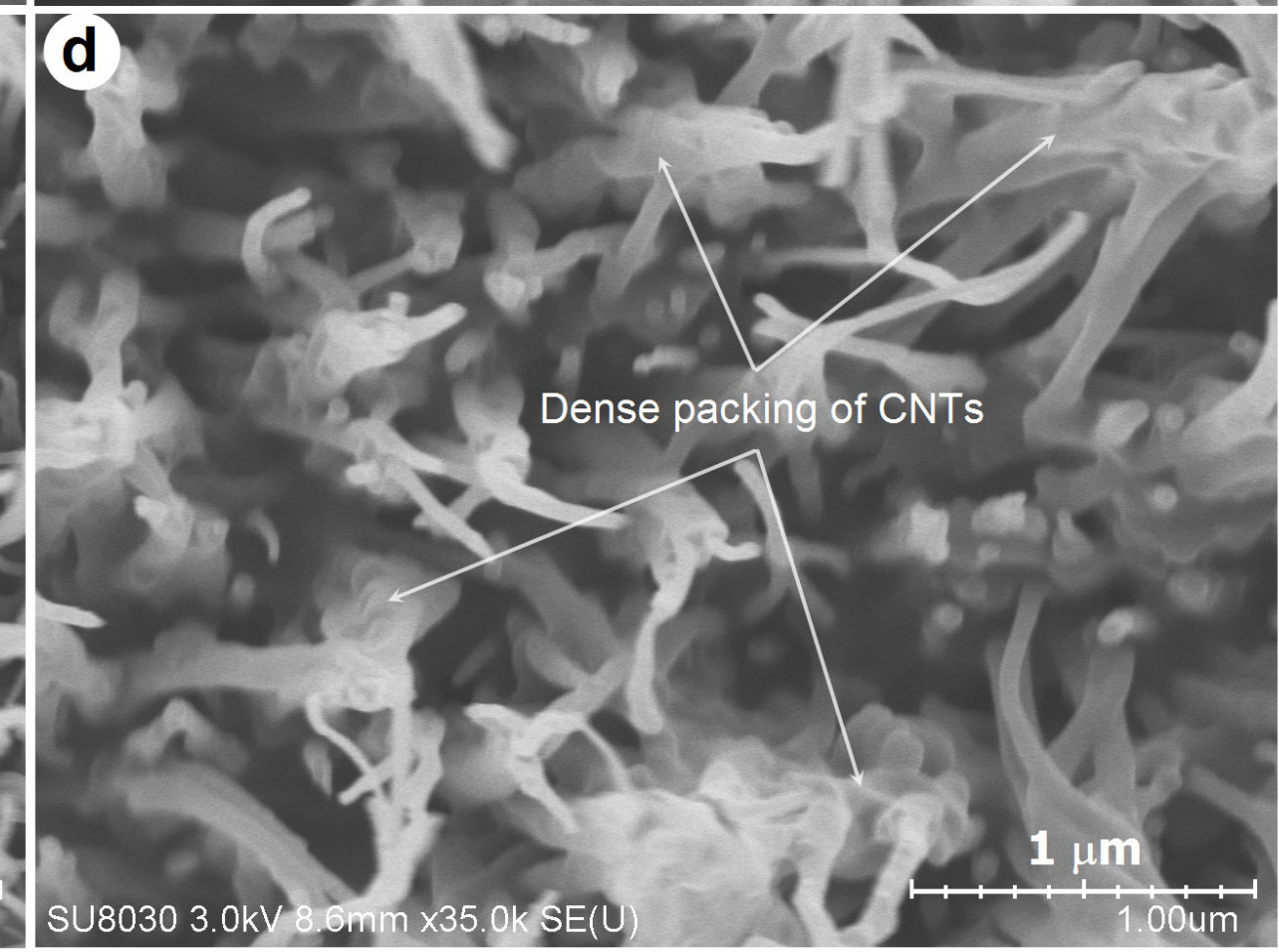

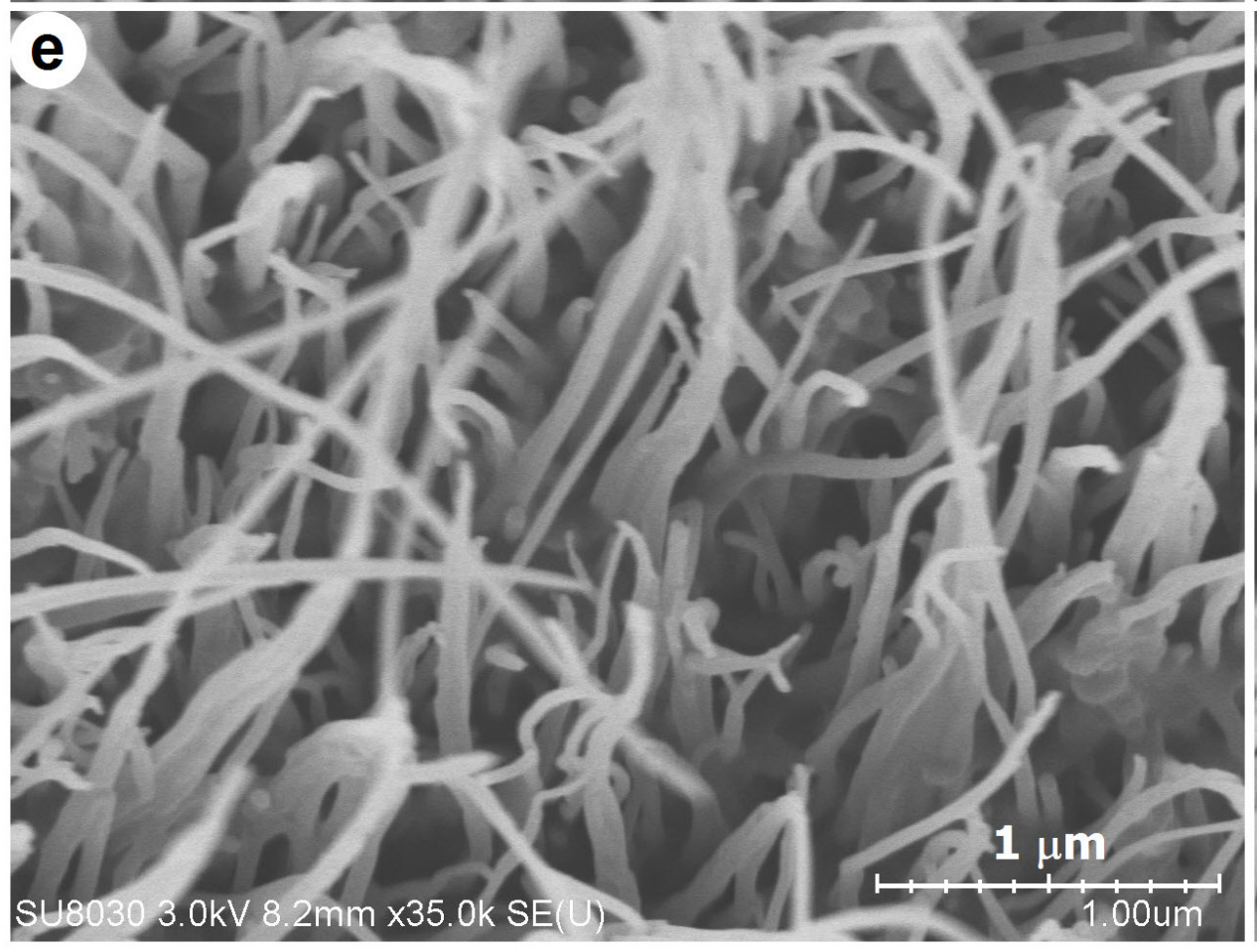

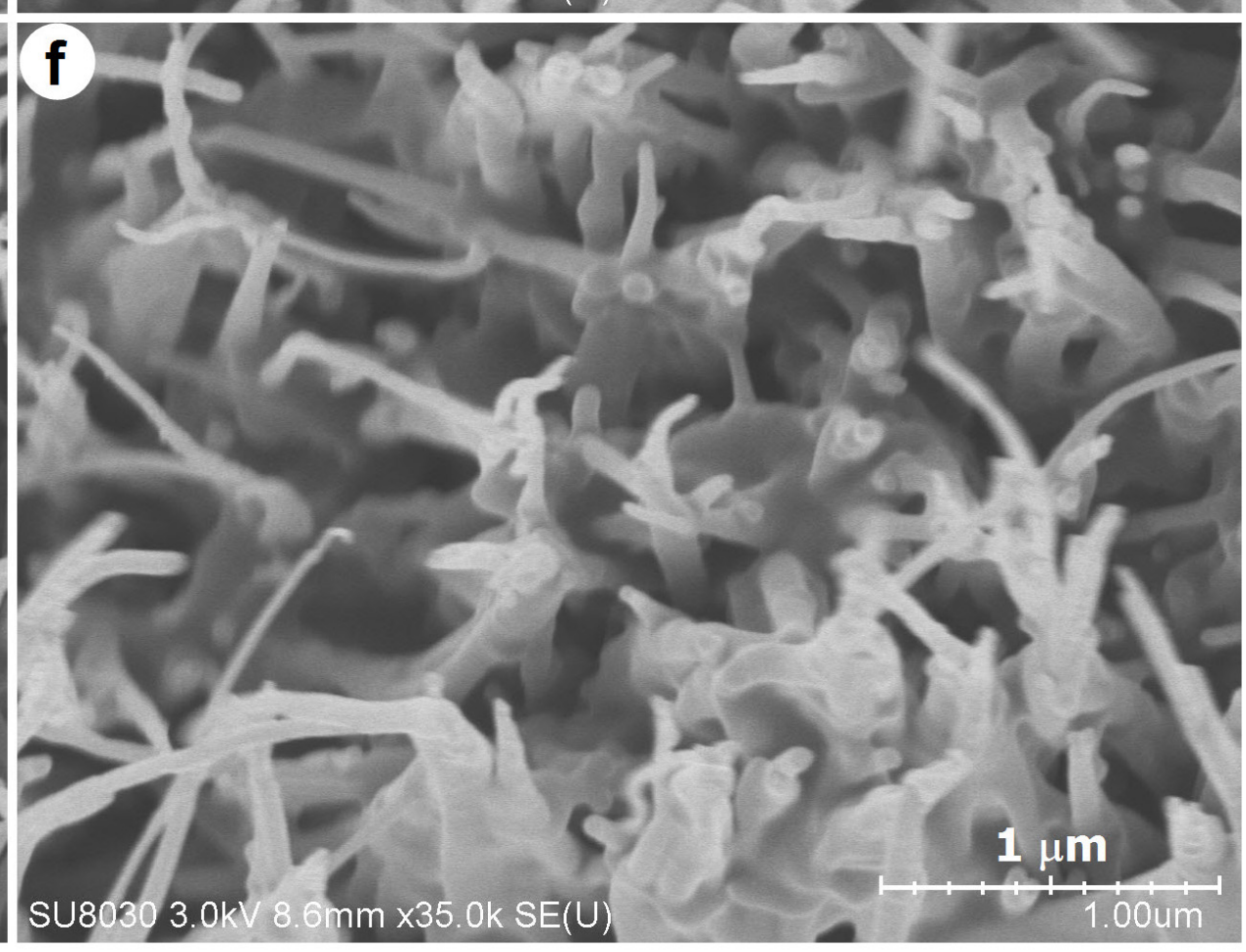


Figure 10

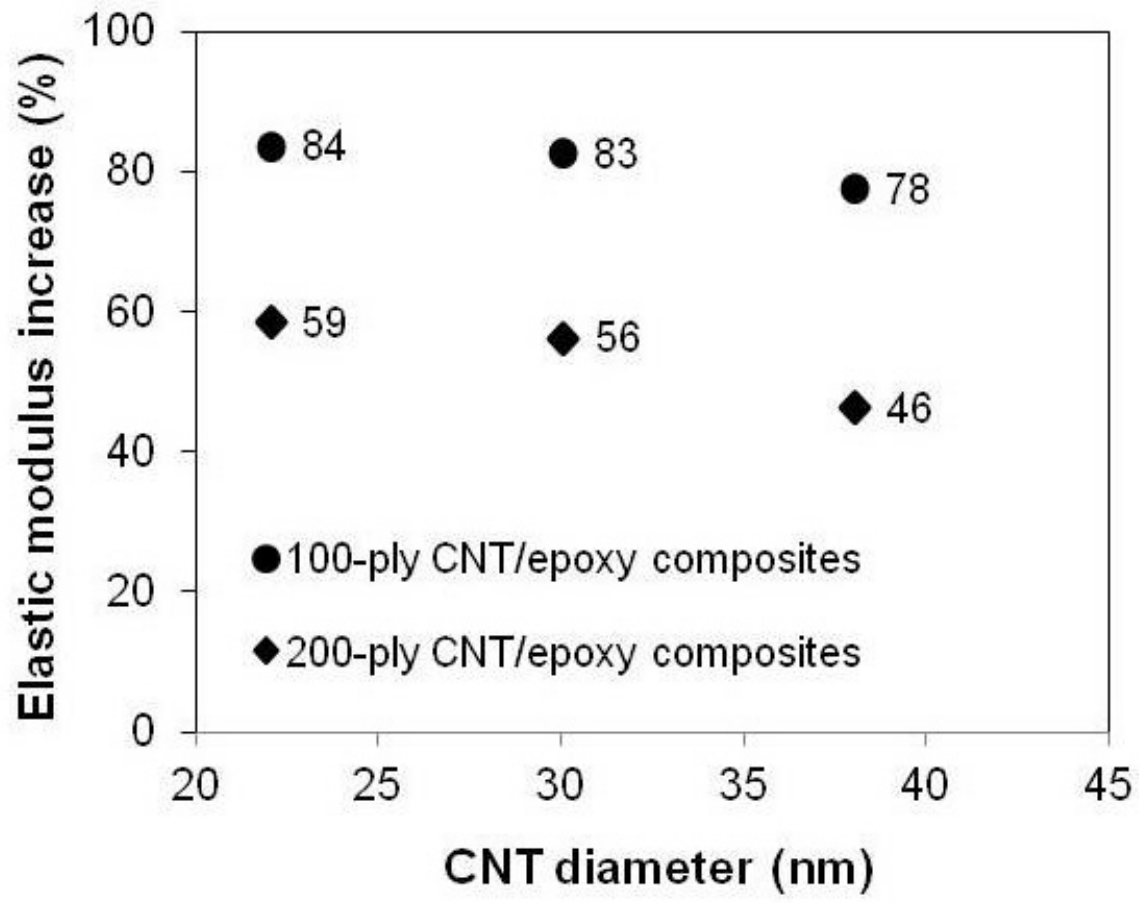


Figure 11

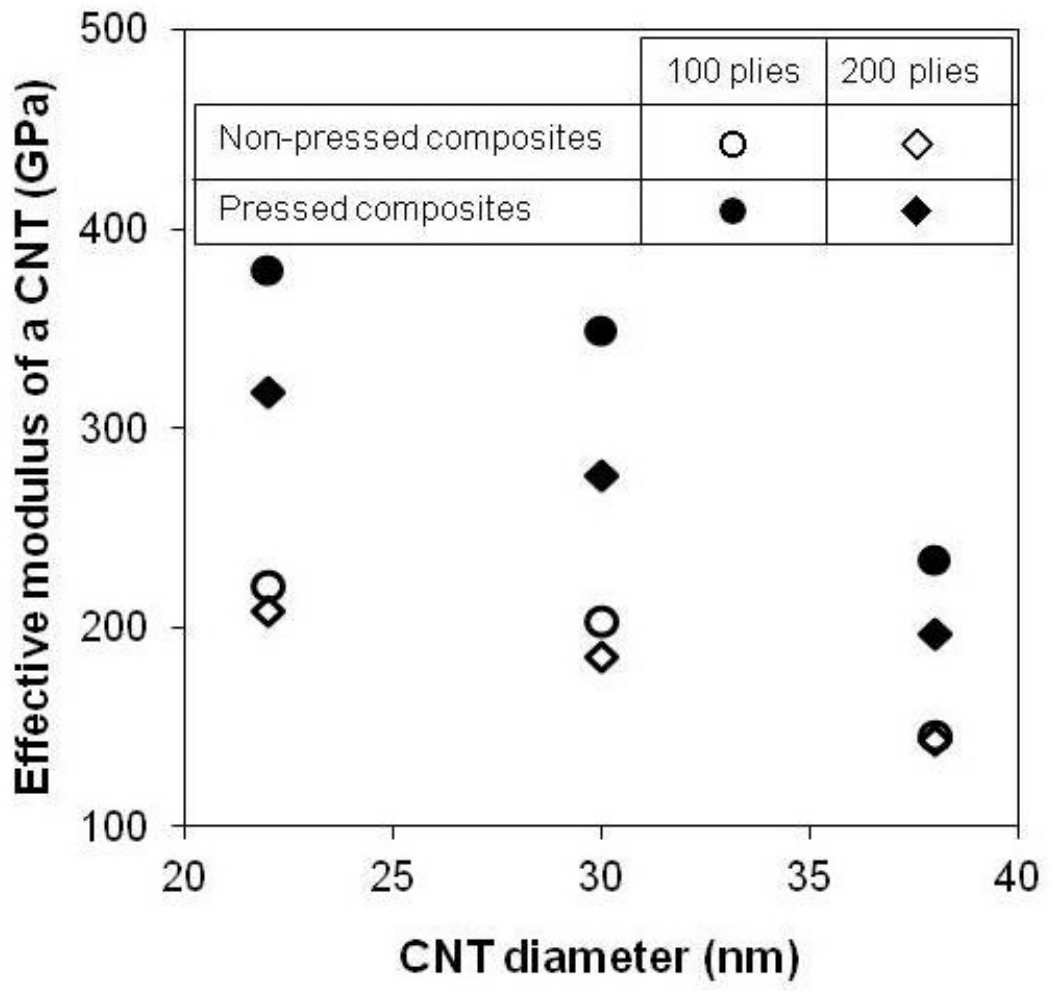


Table 1 - Properties of the non-pressed and pressed composites with the different CNTs

Table 2 - Properties of the non-pressed and pressed 100-ply CNT sheets

Table 3 - Change of intensity ratio $\left(I_{\mathrm{G}} / I_{\mathrm{D}}\right)$ and G-band intensity ratio $(R)$ 
Table 1

\begin{tabular}{|c|c|c|c|c|c|c|}
\hline Materials & CNT plies & $\begin{array}{c}\text { Mean diameter } \\
\text { CNTs }\end{array}$ & $\begin{array}{c}\text { Thickness } \\
\text { (mm) }\end{array}$ & $\begin{array}{c}\text { Mass loss }{ }^{*} \\
(\%)\end{array}$ & $\begin{array}{l}\text { CNT mass } \\
\text { fraction } \\
(\%)\end{array}$ & $\begin{array}{l}\text { CNT volume } \\
\text { fraction } \\
\text { (vol. \%) }\end{array}$ \\
\hline Epoxy resin & - & - & - & 87.9 & - & - \\
\hline \multirow[t]{3}{*}{ CNTs } & - & - & - & 2.59 & - & - \\
\hline & & 22 & $9-10$ & 56.2 & 37.2 & 26.2 \\
\hline & 100 & 30 & 9-11 & 54.8 & 38.9 & 27.6 \\
\hline \multirow{6}{*}{$\begin{array}{l}\text { Non-pressed } \\
\text { composites }\end{array}$} & & $38^{* *}$ & $9-11$ & 45.2 & 50.0 & 37.5 \\
\hline & & 22 & $15-17$ & 44.5 & 50.9 & 38.4 \\
\hline & 200 & 30 & $15-19$ & 40.9 & 55.0 & 42.4 \\
\hline & & 38 & $16-20$ & 32.1 & 65.5 & 53.2 \\
\hline & & 22 & $8-9$ & 53.9 & 39.9 & 28.4 \\
\hline & 100 & 30 & $8-10$ & 52.5 & 41.5 & 29.8 \\
\hline \multirow{4}{*}{$\begin{array}{l}\text { Pressed } \\
\text { composites }\end{array}$} & & $38^{* *}$ & $8-10$ & 41.1 & 54.8 & 42.1 \\
\hline & & 22 & $14-16$ & 42.8 & 52.9 & 40.2 \\
\hline & 200 & 30 & $15-17$ & 39.0 & 57.4 & 44.7 \\
\hline & & 38 & $15-18$ & 29.0 & 69.1 & 57.3 \\
\hline
\end{tabular}

${ }^{*}$ Mass loss was measured between $150^{\circ} \mathrm{C}$ and $750^{\circ} \mathrm{C}$.

${ }^{* *}$ Results were referred from our earlier report [23]. 
Table 2

\begin{tabular}{|c|c|c|c|c|c|c|}
\hline $\begin{array}{c}\text { CNT sheet } \\
\text { sample }\end{array}$ & $\begin{array}{l}\text { CNT sheet } \\
\text { processing }\end{array}$ & $\begin{array}{c}\text { Thickness } \\
(\mu \mathrm{m})\end{array}$ & $\begin{array}{c}\text { Areal } \\
\text { weight } \\
\left(\mathrm{g} / \mathrm{m}^{2}\right)\end{array}$ & $\begin{array}{l}\text { Tensile } \\
\text { strength } \\
\text { (MPa) }\end{array}$ & $\begin{array}{c}\text { Elastic } \\
\text { modulus } \\
\text { (GPa) }\end{array}$ & $\begin{array}{c}\text { Strain at max } \\
\text { stress } \\
(\%)\end{array}$ \\
\hline \multirow{2}{*}{ CNT-22 } & Non-pressing & $5-7$ & 6.5 & $173.6 \pm 20.6$ & $10.8 \pm 1.9$ & $2.64 \pm 0.36$ \\
\hline & Pressing & $4-6$ & 6.2 & $349.7 \pm 46.8$ & $48.7 \pm 7.9$ & $0.84 \pm 0.07$ \\
\hline \multirow{2}{*}{ CNT-30 } & Non-pressing & $5-7$ & 6.8 & $163.3 \pm 16.6$ & $9.3 \pm 1.0$ & $2.37 \pm 0.36$ \\
\hline & Pressing & $4-6$ & 6.5 & $327.4 \pm 26.8$ & $41.9 \pm 4.8$ & $0.80 \pm 0.06$ \\
\hline \multirow{2}{*}{ CNT-38* } & Non-pressing & $6-8$ & 7.5 & $88.6 \pm 9.2$ & $6.1 \pm 0.7$ & $3.29 \pm 0.42$ \\
\hline & Pressing & $5-7$ & 7.2 & $211.8 \pm 16.7$ & $35.7 \pm 3.5$ & $0.71 \pm 0.06$ \\
\hline
\end{tabular}

* Results were referred from our earlier report [23]. 


\section{Table 3}

\begin{tabular}{ccccc}
\hline \multirow{2}{*}{$\begin{array}{c}\text { Composite } \\
\text { sample }\end{array}$} & CNT sheet & \multicolumn{2}{c}{ Intensity ratio $\left(I_{\mathrm{G}} / \mathrm{I}_{\mathrm{D}}\right)$} & $\begin{array}{c}\text { G-band intensity ratio } \\
(R)\end{array}$ \\
\cline { 3 - 4 } & processing & $0^{\circ}$ & $90^{\circ}$ & 1.31 \\
200-ply & Non-pressing & 2.21 & 2.67 & 1.75 \\
CNT-22 & Pressing & 2.25 & 2.74 & 1.39 \\
$200-p l y$ & Non-pressing & 2.27 & 2.76 & 1.87 \\
CNT-30 & Pressing & 2.28 & 2.83 & 1.43 \\
200-ply & Non-pressing & 2.75 & 3.28 & 1.99 \\
CNT-38 & Pressing & 2.85 & 3.42 & \\
\hline
\end{tabular}

